\title{
$\$$ Research Square

\section{A Regime Shift in Seasonal Total Antarctic Sea Ice Extent in the 20th Century}

Ryan Fogt ( $\square$ fogtr@ohio.edu )

Ohio University https://orcid.org/0000-0002-5398-3990

Amanda Sleinkofer

Ohio University

Marilyn Raphael

UCLA https://orcid.org/0000-0003-3199-942X

Mark Handcock

Department of Statistics, University of California, Los Angeles, USA

\section{Article}

Keywords: Antarctic sea ice, climate, climate modelling

Posted Date: August 24th, 2021

DOI: https://doi.org/10.21203/rs.3.rs-828060/v1

License: (9) This work is licensed under a Creative Commons Attribution 4.0 International License. Read Full License

Version of Record: A version of this preprint was published at Nature Climate Change on January 10th, 2022. See the published version at https://doi.org/10.1038/s41558-021-01254-9. 


\section{A Regime Shift in Seasonal Total Antarctic Sea Ice Extent in the 20 ${ }^{\text {th }}$}

2 Century

3

4 Ryan L. Fogt ${ }^{1}$, Amanda M. Sleinkofer ${ }^{1}$, Marilyn N. Raphael ${ }^{2}$, Mark S. Handcock ${ }^{3}$

5

$6{ }^{1}$ Department of Geography and Scalia Laboratory for Atmospheric Analysis, Ohio University, 7 Athens, $\mathrm{OH}$

$8 \quad{ }^{2}$ Department of Geography, University of California - Los Angeles, Los Angeles, CA

$9{ }^{3}$ Department of Statistics, University of California - Los Angeles, Los Angeles, CA

Corresponding author email: fogtr@ohio.edu 


\section{Abstract}

15 In stark contrast to the Arctic, there have been statistically significant positive trends in total

16 Antarctic sea ice extent since 1979, despite a sudden decline in sea ice in $2016^{1-5}$ and increasing

17 greenhouse gas concentrations. Attributing Antarctic sea ice trends is complicated by the fact

18 that most coupled climate models show negative trends in sea ice extent since 1979, opposite of

19 that observed ${ }^{6-8}$. Additionally, the short record of sea ice extent (beginning in 1979), coupled

20 with the high degree of interannual variability, make the record too short to fully understand the

21 historical context of these recent changes ${ }^{9}$. Here we show, using new robust observation-based

22 reconstructions, that 1) these observed recent increases in Antarctic sea ice extent are unique in

23 the context of the $20^{\text {th }}$ century and 2) the observed trends are juxtaposed against statistically

24 significant decreases in sea ice extent throughout much of the early and middle $20^{\text {th }}$ century.

25 These reconstructions are the first to provide reliable estimates of total sea ice extent surrounding

26 the continent; previous proxy-based reconstructions are limited ${ }^{10}$. Importantly, the

27 reconstructions continue to show the high degree of interannual Antarctic sea ice extent

28 variability that is marked with frequent sudden changes, such as observed in 2016, which stress

29 the importance of a longer historical context when assessing and attributing observed trends in

30 Antarctic climate ${ }^{9}$. Our reconstructions are skillful enough to be used in climate models to allow

31 better understanding of the interconnected nature of the Antarctic climate system and to improve

32 predictions of the future state of Antarctic climate.

Main

35 Sea ice is a critically important component of the very complex Antarctic climate system.

36 Ecologically, sea ice is habitat ${ }^{11}$. Physically, it modulates the ocean-atmosphere exchange of

37 fluxes, helps maintain the equator-pole temperature gradient and its formation maintains the

38 global overturning circulation ${ }^{12-15}$. Sea ice is also one of the most challenging essential climate 
39 variables to understand. Its variability is driven by changes in the atmosphere and ocean, which

40 interact with each other, and operate on different timescales ${ }^{16}$. The remote nature of Antarctica

41 means that there are very few in situ measurements of the atmosphere or ocean surrounding

42 Antarctica where the sea ice forms, and our understanding of its variability depends largely upon

43 satellite observations ${ }^{17,18}$. Satellite measurements of Antarctic sea ice extent indicate weak, but

44 statistically significant increases in total sea ice around Antarctica from 1979-2016, followed by

45 a sharp decline to below average values in 2016 and a record low in summer 2017, before

46 returning to average by austral summer 2020. While the total Antarctic sea ice extent exhibits a

47 positive trend ${ }^{2}$ (contrary to Arctic sea ice extent ${ }^{19}$ ), there is a strong regionality ${ }^{1}$ and seasonality ${ }^{4}$

48 to the trends and they can be of opposite sign. Analyses of the temporal and spatial variability

49 in Antarctic sea ice have been attempted ${ }^{20-23,23,24}$ but a thorough understanding is limited because

50 the sparsity of in situ observations and the brevity of the satellite record mean that their temporal

51 uniqueness cannot be easily assessed ${ }^{9}$. Their future change is also uncertain, since coupled

52 climate models used in both the Intergovernmental Panel on Climate Change (IPCC) $5^{\text {th }}$ and the

53 most recent $6^{\text {th }}$ assessment reports fail to reproduce the observed increases in Antarctic sea ice

54 and instead most show widespread decreases around Antarctica ${ }^{6-8}$.

55 To improve the scientific understanding of Antarctic sea ice variability, several

56 reconstructions of Antarctic sea ice have been completed ${ }^{10,25,26}$. These are primarily based on

57 one of two types of proxy data: ice cores from the Antarctic ice sheet, or ocean sediments from

58 the ocean floor below where the ice forms. While these reconstructions substantially extend the

59 short observational record, they have their own limitations. Their main challenges are that they

60 only represent sea ice conditions in a certain area (or sometimes, at a certain point along the ice

61 edge), and they often can only resolve annual mean sea ice conditions or the sea ice extent during 
62 a specific season ${ }^{10}$. Even model-based simulations of past sea ice that assimilate proxy records

63 for sea ice are not able to provide more detail on the temporal variability of Antarctic sea ice, as

64 these are similarly limited by the resolution of the proxy data incorporated into the model ${ }^{27}$.

65

66

67

68

69

70

71 first estimates of seasonally resolved Antarctic total sea ice extent during the $20^{\text {th }}$ century (Fig.

72 1). The ensemble mean (blue line in Fig. 1), taken as the average of the more than 200,000 sums

73 of sector reconstructions, is well-correlated with the observations $(r>0.79)$. Further, the large

74 number of ensembles for the total sea ice extent reconstruction allows for a time-varying

75 assessment of reconstruction uncertainty (gray shading in Fig. 1). Our reconstruction clearly

76 captures the positive trend in observations prior to $2016^{2}$, and the sudden decline in $2016^{5,23,29}$

77 lies within the reconstruction uncertainty. Notably, our total sea ice reconstructions outperform

78 (based on correlations with observations and their ability to reproduce trends) other proxy-based

79 reconstructions ${ }^{10,25-27}$, better resolving interannual Antarctic sea ice variability, trends, and

80 changes than other existing estimates which only provide information for specific sectors, the

81 annual mean, or a certain season.

82 Our ensemble reconstructions are based on a principal component regression model,

83 successfully employed in previous Antarctic climate reconstructions ${ }^{30-33}$. At the heart of this

84 model is the strong connection sea ice shares with regional and large-scale climate variability, 
85 captured through a network of 30 long-term stations across the Southern Hemisphere (SH) and

86 indices of climate variability extending back to 1905 (Supplementary Fig. S1). Of particular

87 note is the station Orcadas, situated near the Antarctic Peninsula, which is the longest continuous

88 atmospheric record poleward of $60^{\circ} \mathrm{S}^{34}$. We verify our reconstructions with an independent

89 leave-one-out cross validation procedure (see Methods). To indirectly account for the

90 comparatively slower role of the ocean (compared to the atmosphere) on driving Antarctic sea

91 ice changes, we also allow for the predictor data to lead the Antarctic sea ice by up to one

92 season, at one-month increments (see Methods). To further evaluate the reconstruction

93 performance, we also use four different skill metrics: correlations of the reconstruction and

94 verification reconstruction with the observed sea ice extent (hereafter, cal $r$ and val $r$,

95 respectively) as well as the reduction of error and coefficient of efficiency (RE and CE,

96 respectively; see Methods).

97 Since the Antarctic sea ice extent is reconstructed separately for five sectors as well as

98 the total, we can further examine the reconstruction performance and provide more detail than

99 previous studies on the historical total Antarctic sea ice extent variability. Figure 2 displays the

100 total seasonal Antarctic sea ice extent represented by three additional reconstructions (see Fig. 2

101 caption for details) along with the ensemble mean from Fig. 1. Correlations with the observed

102 total Antarctic sea ice extent exceed 0.69 for all seasons for each configuration. Except for SON,

103 the reconstructions for the sum of the sectors are more highly correlated with the observed than

104 for the reconstruction specifically calibrated to the observed total Antarctic sea ice (red line).

105 This fact also validates the skill of the sector reconstructions, as their sum was not calibrated to

106 the observed total sea ice extent during the reconstruction model. Further, the correlations of

107 each reconstruction with the ensemble mean from Fig. 1 (given at the bottom of each panel in 
108 Fig. 2) are above 0.56 (comparable to and often exceeding the correlation of existing proxy-

109 based reconstructions with observations) ${ }^{10,25-27}$. These high correlations between the various

110 reconstructions of the total sea ice extent demonstrate that the reconstructions are fairly

111 stationary across the large ensemble and not overly sensitive to particular predictor data.

112 Collectively, the larger variance inherent in the three individual total sea ice reconstructions

113 (compared to the ensemble mean) in Fig. 2 allow us to conclude that sudden changes in the total

114 Antarctic sea ice extent as observed in 2016 have occurred numerous times in the past century,

115 including large increases from one year to the next.

116 The overall skill across all sectors and ensemble members further indicate that the

117 reconstructions are robust (Fig. 3); perfect reconstructions will reach 1.0 for all skill metrics, and

118 positive values for the RE and $\mathrm{CE}$ indicate superior performance of the reconstruction and

119 validation reconstruction compared to the climatological mean ${ }^{35}$. The boxplots for all ensemble

120 reconstructions (with the number of ensembles given for each season) are in blue, while the

121 reconstructions with the best fit to the observed sea ice, a subset of only 6 reconstructions ( 1 for

122 each sector, and the total) are given in red. Here, the best fit reconstruction is chosen as the

123 reconstruction with the highest $\mathrm{CE}$ since this is the hardest skill metric to pass, unless this

124 reconstruction indicates potential model overfitting. Overfitting was determined using an F-test

125 of the variances of the reconstruction compared to observations. If the variances of the

126 reconstruction with highest $\mathrm{CE}$ were determined unequal $(p<0.01)$ in the reconstruction during

127 1905-1978 (the reconstruction period) compared to the observed variance, an alternate

128 reconstruction with the next highest $\mathrm{CE}$ that maintained similar variances as observed (where

129 possible) was selected as the best fit reconstruction. 
The median reconstruction skill for all four metrics is highest in SON, with similar

131 performance in the remaining seasons. Only a few reconstruction ensemble members have skill

132 metrics below zero in DJF and SON, otherwise across the large ensemble meaningful

133 reconstructions are produced for all sectors and seasons. The best fit reconstructions have skill

134 metrics at or above 0.60; indeed the total sea ice extent reconstructions in Figs. 1 and 2 are often

135 the least skillful reconstructions we produce. The lower skill for total Antarctic sea ice extent, 136 compared to performance at the regional or sector level, relates to the fact that the total Antarctic

137 sea ice extent is influenced by many regional processes that often offset and or cancel each other, 138 as seen in sea ice extent trends in the Ross Sea compared to the Amundsen and Bellingshausen

139 Seas ${ }^{2,16,20}$. Similar to the reconstructions, sea ice forecasts perform much better for individual 140 sectors than they do for the total Antarctic-wide sea ice ${ }^{36}$. These sectoral differences are also why 141 a circum-Antarctic proxy-based reconstruction has not been possible, to date ${ }^{10,26}$.

\section{A Regime Shift in $\mathbf{2 0}^{\text {th }}$ Century Antarctic Sea Ice Extent}

144 The most dramatic new finding from the reconstructions is the changes in the trends 145 throughout time (Fig. 4). By now nearly tripling the length of the observed data timeseries, the 146 reconstructions provide a clear, consistent story of the historical importance of the observed

147 Antarctic sea ice extent trends. The comparatively short observational period (Fig. 4, left 148 column) shows strong positive trends in Antarctic sea ice, especially for periods ending in 2014 149 (when Antarctic sea ice extent reached its record maximum based on satellite measurements ${ }^{2}$ ) to 150 2016, prior to the marked decline. The increase in total Antarctic sea ice extent over the satellite

151 record is in stark contrast to rapid, widespread declines in Arctic sea ice over the same time 152 period $^{19}$. As discussed earlier, the Antarctic sea ice extent trends weaken considerably for ending 
153 years after 2016, and are only statistically significant $(p<0.10)$ in JJA if the ending year of the

154 trends is after 2016 and the starting year is before the mid-1980s (Fig. 4, left panel of third row).

155 Indeed, the positive trends seen before 2016 switch to negative (albeit, not statistically

156 significant) trends for ending years after 2016 in DJF (first plot in top row). However, these

157 trends are only based on a little over 40 years of observed satellite data, making it a challenge to

158 resolve decadal-scale variability and assess their historical significance from observations alone9

159 The short duration of the observed trends in the context of variability since the start of the

$16020^{\text {th }}$ century is visualized as the relatively small box in the upper right panels of the remaining

161 three columns of Fig. 4, which show trends from the reconstructions for various time periods

162 throughout the $20^{\text {th }}$ century. The positive trends since 1979 in both observations and

163 reconstructions are unique in the context of Antarctic sea ice variability over the last century.

164 Given that our reconstructions are the first to fully resolve variations across the seasons, it is now

165 shown that these are the only statistically significant $(p<0.10)$ increases in Antarctic sea ice

166 extent across for any time period simultaneously in all four seasons since 1905.

167 Moreover, in most seasons, the positive trends in the observational period stand in

168 marked contrast to statistically significant $(p<0.10)$ negative trends in the early to mid- $20^{\text {th }}$

169 century, especially prevalent in the ensemble mean (Fig. 4, rightmost column, and Fig. 1). The

170 negative trends in the early to mid $20^{\text {th }}$ century reach high levels of statistical significance

$171(p<0.05$, stippled in Fig. 4$)$ in all but SON, where they are weaker and there is more variation in

172 the sign and magnitude of the sea ice trends among the various estimates of total Antarctic sea

173 ice extent. It should be noted that the insignificant positive trends for the best fit reconstruction

174 in MAM (second column, second row) is an outlier for this season - it is the only ensemble

175 member for the total sea ice reconstruction in MAM to display weakly positive trends in 
176 Antarctic sea ice (not shown). Combined with the short observations timeseries, the

177 reconstructions strongly suggest a regime shift in Antarctic sea ice extent in the middle of the

$17820^{\text {th }}$ century, where long-term declines in Antarctic sea ice extent prior to 1960 are juxtaposed by

179 strong increases in the late $20^{\text {th }}$ century which encompass the satellite observations (left column

180 of Fig. 4 and boxes in other columns). These trends also suggest that the observed period, in

181 addition to being too short to fully capture the range of true historical variability of Antarctic sea

182 ice extent ${ }^{9}$, started at a time of relatively low sea ice extent in the context of the last century,

183 giving rise to a strong positive trend that is part of multidecadal scale variability (Figs. 1 and 2).

184 Although difficult to compare (due to the aforementioned limitations of other existing

185 reconstructions), many other proxy-based reconstructions of Antarctic sea ice extent outside of

186 the Amundsen-Bellingshausen Seas hint at a similar, but weaker, reversal of sea ice changes

187 from the early to late $20^{\text {th }}$ century, especially in the Ross and Weddell Seas ${ }^{10,25,27}$. Although the

188 observed trends are not produced as well as our reconstructions, the most recently published set

189 of Antarctic sea ice extent reconstructions ${ }^{26}$ based on six proxies similarly confirm the idea of a

190 mid-20 $0^{\text {th }}$ century regime shift in Antarctic sea ice, with widespread decreases in annual mean

191 Antarctic sea in many sectors in the early to mid $20^{\text {th }}$ century that switch to increases in Antarctic

192 sea ice extent during the observed satellite period.

193 Since the regime shift in the total sea ice extent reconstruction is most prominent in

194 austral winter (JJA, Fig. 4), our reconstruction approach allows us to further examine this

195 spatially by looking at the changes across the sectors (Fig. 5). Notably, the low-frequency

196 versions of the sector reconstructions and observations are also highly correlated ( $r>0.8$, bottom

197 correlation numbers in each timeseries in Fig. 5), further validating the reconstruction approach

198 as the reconstruction model was calibrated explicitly for interannual variations. The high skill in 
199 reproducing these variations translates into similar high skill in the low-frequency decadal scale

200 variations. Across the sectors, it is clear that the regime shift is not equally pronounced in all

201 sectors (Fig. 5), highlighting the known independent nature of Antarctic sea ice in various sectors

202 around the continent ${ }^{28}$. The differences among the sectors also show that the mid- $20^{\text {th }}$ century

203 Antarctic sea ice extent regime shift is not an artifact of the reconstruction or a gross error in the

204 data employed to estimate pre-satellite Antarctic sea ice conditions (as this would likely be seen

205 across all sectors). Indeed, the regime shift from early to mid $20^{\text {th }}$ century ice loss to late $20^{\text {th }}$

206 century ice gains is most pronounced in the King Hakon VII and Ross Sea sectors (Figs. 5b,d).

207 For the Ross Sea, our best fit reconstruction indicates the austral winter sea ice decreased -

$2080.187 \pm 0.104$ standard deviations per decade $(p<0.01)$ during $1905-1978$, followed by an increase 209 of $0.236 \pm 0.207$ standard deviations per decade $(p<0.05)$ from 1979-2020; the Ross Sea sector is

210 the only sector to display a statistically significant $(p<0.05)$ increase in Antarctic sea ice extent

211 during 1979-2020 in our reconstructions and observations. Furthermore, the significant observed

212 increase in Antarctic sea ice extent during 1979-2020 for the Ross Sea sector $(0.268 \pm 0.239$

213 standard deviations per decade) is also comparable to the trend in our reconstruction. Similarly

214 supporting a regime shift, the 1905-1978 trend (-0.144 \pm 0.097 standard deviations per decade,

$215 p<0.01)$ and the $1979-2020$ trend $(0.116+0.245$ standard deviations per decade, $p>0.10)$ in the

216 best fit reconstruction for the King Hakon sector are statistically different from each other at

$217 p<0.05$.

218 Similar to patterns in sea ice trends during the satellite era ${ }^{22,24,37}$, our sector

219 reconstructions also clearly indicate an offsetting behavior between the Ross (Fig. 4d) and

220 Bellingshausen-Amundsen Seas (Fig. 5c) throughout the $20^{\text {th }}$ century. In the Bellingshausen-

221 Amundsen Seas, the best fit reconstruction demonstrates that ice was increasing during 1905- 
$2221978(0.138 \pm 0.109$ standard deviations per decade, $p<0.05)$, in opposition to the decreases in the

223 Ross Sector in the same time period (Fig. 5d). The trend switched to a weakly and statistically

224 insignificant negative trend after 1979 in the Bellingshausen-Amundsen Seas, similar to

225 observed, and again in opposition to the change in the Ross Sea (Figs. 4c,d). The opposing

226 behavior of sea ice in this sector, at least in observations, can largely be linked to changes in the

227 atmospheric circulation related to the Amundsen Sea Low (ASL), a semipermanent region of low

228 pressure. When particularly strong, the winds associated with the ASL act to push sea ice toward

229 the Antarctic coast and Peninsula in the Bellingshausen Sea, while pushing it equatorward in the

230 adjacent Ross Sea ${ }^{1,22,38,39}$. We note that our finding supporting the persistence in the $20^{\text {th }}$ century

231 of the observed opposing relationship between the Ross and Bellingshausen-Amundsen Seas was

232 not found in another Antarctic sea ice extent reconstruction study ${ }^{27}$, which may be due to their

233 lower reconstruction skill, especially in the Bellingshausen Sea (only our Ross Sea

234 reconstruction is positively correlated with theirs during the $20^{\text {th }}$ century). We also note that the

235 increase in sea ice extent in the early portion of the $20^{\text {th }}$ century in our reconstruction for the

236 Bellinghausen-Amundsen seas is inconsistent with other proxy-based reconstructions, which

237 suggest a persistent decrease of sea ice in this sector throughout the $20^{\text {th }}$ century ${ }^{25,27}$. These

238 differences may arise from limitations of both our reconstruction and existing proxy-based

239 reconstructions, which capture various processes that are related to Antarctic sea ice extent;

240 however, we note that our reconstructions preserve known physical relationships throughout the

$24120^{\text {th }}$ century between the Ross and Bellingshausen-Seas and are better calibrated to observations.

242 Regardless, we urge caution in using a specific time period to investigate a trend, as Fig. 4

243 indicates the trends (both in magnitude and statistical significance) are sensitive to the starting 
244 and ending dates, and the regime shift does not begin simultaneously across the sectors nor the

245 various ensemble members in the reconstruction.

246 Given the complexities of the Antarctic sea ice trends (both spatially and temporally),

247 interpreting the causality of this pronounced regime shift remains a challenge. Observational

248 records near Antarctica generally only reach back to the International Geophysical Year (1957-

$2491958)^{40}$, and because the trends that stand in contrast to the observed period originated in the

250 early $20^{\text {th }}$ century and continued only into the middle $20^{\text {th }}$ century, there is not a pronounced

251 signal in many of the closest meteorological measurements ${ }^{41,42}$. Attribution studies are further

252 complicated since climate models generally produce widespread Antarctic ice loss since 1979,

253 opposite that of observations ${ }^{6-8}$. Yet, the regional and time-sensitive character of the reversal

254 strongly hints at the important role of pronounced decadal scale variability in both the

255 atmosphere and ocean. Observations of the ocean are even more sparse near Antarctica, but

256 previous work suggests that convection in the Southern Ocean contributes strongly to observed

257 trends in temperature and sea ice near Antarctica, especially on longer timescales ${ }^{16,43,44}$. From

258 the atmospheric perspective, earlier work examining trends in the midlatitude pressure

259 observations used as predictors in this study show patterns of decadally-varying trends with

260 synchronous, but opposing variability between the mid and high latitudes of the Southern

261 Hemisphere ${ }^{45}$. This study connected a considerable portion of the broad changes in atmospheric

262 pressure (circulation) across the entire Southern Hemisphere to the Southern Annular Mode

263 (SAM), with negative pressure trends in many seasons in the early $20^{\text {th }}$ century that became

264 positive in the late $20^{\text {th }}$ century. The SAM has also been suggested to influence mid $20^{\text {th }}$ century

265 Antarctic sea ice regime shifts in other work ${ }^{26}$, although it is necessary to note that the SAM

266 index used by ref. 26 (based on gridded atmospheric reanalysis products spanning the entire $20^{\text {th }}$ 
267 century) is known to have artificial trends throughout the $20^{\text {th }}$ century due to changes in data

268 availability in the underlying products used to create the index ${ }^{46,47}$. Perhaps more importantly

269 due to the regional variations in the trends, Fogt and Connolly (2021) also note that regional

270 changes in the atmospheric circulation were often associated with multi-decadal tropical

271 variability. In particular, significant $(p<0.05)$ shifts in the Interdecadal Pacific Oscillation

272 (negative trends in early and late $20^{\text {th }}$ century, to positive trends in the mid $20^{\text {th }}$ century), a

273 pattern known to especially impact Antarctic sea ice variations from the Ross to Weddell

274 Seas ${ }^{23,24,37}$, likely also plays an important role. Given that all the JJA best fit reconstructions

275 from the Ross to Weddell Seas in Fig. 4 employ many different subsets of tropical SST indices,

276 including the IPO, the importance of decadal scale tropical variability cannot be overstated.

277 Analysis of these contributions is part of future work, yet hopefully the newly generated

278 reconstructions presented here will promote an increase in research from many disciplines aimed

279 at further interpreting and unlocking historical variations in Antarctic sea ice extent during the

$28020^{\text {th }}$ century.

281

282 Discussion and Summary

283 The brevity of the timeseries of satellite-observed Antarctic sea ice, combined with its

284 large interannual variability make it very challenging to understand its behavior and to predict its

285 future. To improve the understanding, we have created and present here, an initial analysis of

286 seasonally-resolved reconstructions of the Antarctic sea ice extent back until 1905. These

287 reconstructions are based on strong relationships the sea ice shares with midlatitude climate

288 (pressure and temperature) and the role that modes of large-scale atmospheric variability play in

289 influencing Antarctic sea ice extent. They are verified using an independently produced 
290 validation reconstruction as well as through an ensemble of reconstructions that vary the

291 predictor data used.

292 Importantly the reconstructions demonstrate high skill, far exceeding that of previous

293 proxy-based reconstructions of Antarctic sea ice extent, and the simple use of the climatological

294 mean from gridded products like the Hadley Center Sea Ice and Sea Surface Temperature data

295 set $^{48}$ that is often used in historical climate model simulations spanning the entire $20^{\text {th }}$ century.

296 Moreover, the reconstructions are the first to provide a seasonally-resolved picture of Antarctic

297 sea ice. We also produce robust reconstructions for five sectors partitioning the ocean around

298 Antarctica.

299 Our reconstructions highlight the large interannual variability observed in Antarctic sea

300 ice extents throughout the early $20^{\text {th }}$ century, with a pronounced regime shift occurring in the

301 middle of the $20^{\text {th }}$ century. This regime shift is characterized by changes in total Antarctic sea

302 ice extent trends, from decreases in seasonal total Antarctic sea ice extent in the early to mid $20^{\text {th }}$

303 century, to the increases in Antarctic sea ice extent seen in observations prior to 2016. Such

304 dramatic changes continue to highlight the importance of having longer records of Antarctic

305 climate to fully encompass the range of historical variability, and the need for historical data

306 rescue to uncover yet unpublished records of Antarctic climate to help place recent changes in a

307 longer context. As these reconstructions are highly skillful, they are also appropriate to use in

308 further research on evaluating climate models and interpreting the precise causes of the regime

309 shifts depicted in these reconstructions.

310

311

312 References 
313 1. Turner, J., Hosking, J. S., Bracegirdle, T. J., Marshall, G. J. \& Phillips, T. Recent changes in 314 Antarctic Sea Ice. Philos. Trans. R. Soc. -Math. Phys. Eng. Sci. 373, 20140163 (2015).

315 2. Parkinson, C. L. A 40-y record reveals gradual Antarctic sea ice increases followed by 316 decreases at rates far exceeding the rates seen in the Arctic. Proc. Natl. Acad. Sci. 116, $317 \quad 14414-14423(2019)$.

318 3. Eayrs, C., Li, X., Raphael, M. N. \& Holland, D. M. Rapid decline in Antarctic sea ice in 319 recent years hints at future change. Nat. Geosci. 14, 460-464 (2021).

320 4. Holland, P. R. The seasonality of Antarctic sea ice trends. Geophys. Res. Lett. 41, 4230-4237 $321 \quad(2014)$.

322 5. Turner, J. et al. Recent Decrease of Summer Sea Ice in the Weddell Sea, Antarctica. 323 Geophys. Res. Lett. 47, (2020).

324 6. Turner, J., Bracegirdle, T. J., Phillips, T., Marshall, G. J. \& Hosking, J. S. An Initial 325 Assessment of Antarctic Sea Ice Extent in the CMIP5 Models. J. Clim. 26, 1473-1484 326 (2013).

327 7. Shu, Q. et al. Assessment of Sea Ice Extent in CMIP6 With Comparison to Observations and 328 CMIP5. Geophys. Res. Lett. 47, (2020).

329 8. Roach, L. A. et al. Antarctic Sea Ice Area in CMIP6. Geophys. Res. Lett. 47, (2020).

330 9. Jones, J. M. et al. Assessing recent trends in high-latitude Southern Hemisphere surface 331 climate. Nat. Clim. Change 6, 917-926 (2016).

332 10. Thomas, E. R. et al. Antarctic Sea Ice Proxies from Marine and Ice Core Archives Suitable 333 for Reconstructing Sea Ice over the Past 2000 Years. Geosciences 9, 506 (2019).

334 11. Massom, R. A. \& Stammerjohn, S. E. Antarctic sea ice change and variability - Physical and 335 ecological implications. Polar Sci. 4, 149-186 (2010). 
336 12. Bitz, C. M., Gent, P. R., Woodgate, R. A., Holland, M. M. \& Lindsay, R. The Influence of

337 Sea Ice on Ocean Heat Uptake in Response to Increasing CO2. J. Clim. 19, 2437-2450

338 (2006).

339 13. Pellichero, V., Sallée, J.-B., Chapman, C. C. \& Downes, S. M. The southern ocean

340 meridional overturning in the sea-ice sector is driven by freshwater fluxes. Nat. Commun. 9,

$341 \quad 1789(2018)$

342 14. Vancoppenolle, M. et al. Role of sea ice in global biogeochemical cycles: emerging views

343 and challenges. Quat. Sci. Rev. 79, 207-230 (2013).

344 15. Williams, G. D. et al. The suppression of Antarctic bottom water formation by melting ice

345 shelves in Prydz Bay. Nat. Commun. 7, 12577 (2016).

346 16. Hobbs, W. R. et al. A review of recent changes in Southern Ocean sea ice, their drivers and

347 forcings. Glob. Planet. Change 143, 228-250 (2016).

348 17. Cavalieri, D. J. \& Parkinson, C. L. Antarctic sea ice variability and trends, 1979-2006. J.

349 Geophys. Res. 113, (2008).

350 18. Parkinson, C. L. \& Cavalieri, D. J. Antarctic sea ice variability and trends, 1979-2010. The

$351 \quad$ Cryosphere 6, 871-880 (2012).

352 19. Stroeve, J. \& Notz, D. Changing state of Arctic sea ice across all seasons. Environ. Res. Lett.

353 13, 103001 (2018).

354 20. Stammerjohn, S. et al. The influence of winds, sea-surface temperature and precipitation 355 anomalies on Antarctic regional sea-ice conditions during IPY 2007. Deep Sea Res. Part II

356 Top. Stud. Oceanogr. 58, 999-1018 (2011). 
357

358

359

360

361

362

363

364

365

366

367

368

369

370

371

372

373

374

375

376

377

378

21. Stammerjohn, S. E., Martinson, D. G., Smith, R. C., Yuan, X. \& Rind, D. Trends in Antarctic annual sea ice retreat and advance and their relation to El Niño-Southern Oscillation and Southern Annular Mode variability. J. Geophys. Res. 113, (2008).

22. Holland, P. R. \& Kwok, R. Wind-driven trends in Antarctic sea-ice drift. Nat. Geosci. 5, $872-875$ (2012).

23. Purich, A. \& England, M. H. Tropical teleconnections to Antarctic sea ice during austral spring 2016 in coupled pacemaker experiments. Geophys. Res. Lett. (2019) doi:10.1029/2019GL082671.

24. Meehl, G. A., Arblaster, J. M., Bitz, C. M., Chung, C. T. Y. \& Teng, H. Antarctic sea-ice expansion between 2000 and 2014 driven by tropical Pacific decadal climate variability. Nat. Geosci. 9, 590-595 (2016).

25. Abram, N. J. et al. Ice core evidence for a 20th century decline of sea ice in the Bellingshausen Sea, Antarctica. J. Geophys. Res. 115, (2010).

26. Yang, J., Xiao, C., Liu, J., Li, S. \& Qin, D. Variability of Antarctic sea ice extent over the past 200 years. Sci. Bull. S2095927321005090 (2021) doi:10.1016/j.scib.2021.07.028.

27. Dalaiden, Q., Goosse, H., Rezsohazy, J. \& Thomas, E. R. Reconstructing atmospheric circulation and sea-ice extent in the West Antarctic over the past 200 years using data assimilation. https://www.researchsquare.com/article/rs-224001/v1 (2021) doi:10.21203/rs.3.rs-224001/v1.

28. Raphael, M. N. \& Hobbs, W. The influence of the large-scale atmospheric circulation on Antarctic sea ice during ice advance and retreat seasons. Geophys. Res. Lett. 41, 5037-5045 (2014). 
29. Stuecker, M. F., Bitz, C. M. \& Armour, K. C. Conditions leading to the unprecedented low Antarctic sea ice extent during the 2016 austral spring season. Geophys. Res. Lett. 44, 90089019 (2017).

30. Fogt, R. L. et al. Antarctic station-based seasonal pressure reconstructions since 1905: 1. Reconstruction evaluation: Antarctic Pressure Evaluation. J. Geophys. Res. Atmospheres 121, 2814-2835 (2016).

31. Fogt, R. L. et al. A twentieth century perspective on summer Antarctic pressure change and variability and contributions from tropical SSTs and ozone depletion. Geophys. Res. Lett. 44, 9918-9927 (2017).

32. Jones, J. M. et al. Historical SAM Variability. Part I: Century-Length Seasonal Reconstructions. J. Clim. 22, 5319-5345 (2009).

33. Fogt, R. L. et al. Seasonal Antarctic pressure variability during the twentieth century from spatially complete reconstructions and CAM5 simulations. Clim. Dyn. (2019) doi:10.1007/s00382-019-04674-8.

34. Zazulie, N., Rusticucci, M. \& Solomon, S. Changes in Climate at High Southern Latitudes: A Unique Daily Record at Orcadas Spanning 1903-2008. J. Clim. 23, 189-196 (2010).

35. Cook, E. R., Meko, D. M., Stahle, D. W. \& Cleaveland, M. K. Drought reconstructions for the continental United States. J. Clim. 12, 1145-1162 (1999).

36. Bushuk, M. et al. Seasonal prediction and predictability of regional Antarctic sea ice. $J$. Clim. 1-68 (2021) doi:10.1175/JCLI-D-20-0965.1.

37. Purich, A. et al. Tropical Pacific SST Drivers of Recent Antarctic Sea Ice Trends. J. Clim. 29, 8931-8948 (2016). 
401 38. Raphael, M. N. et al. The Amundsen Sea Low: Variability, Change, and Impact on Antarctic 402 Climate. Bull. Am. Meteorol. Soc. 97, 111-121 (2016).

403 39. Hosking, J. S., Orr, A., Marshall, G. J., Turner, J. \& Phillips, T. The Influence of the 404 Amundsen-Bellingshausen Seas Low on the Climate of West Antarctica and Its 405 Representation in Coupled Climate Model Simulations. J. Clim. 26, 6633-6648 (2013).

406 40. Turner, J. et al. The SCAR READER project: Toward a high-quality database of mean 407 Antarctic meteorological observations. J. Clim. 17, 2890-2898 (2004).

408 41. Turner, J. et al. Antarctic climate change during the last 50 years. Int. J. Climatol. 25, 279$409294(2005)$.

410 42. Turner, J. et al. Antarctic temperature variability and change from station data. Int. J. $411 \quad$ Climatol. (2019) doi:10.1002/joc.6378.

412 43. Fan, T., Deser, C. \& Schneider, D. P. Recent Antarctic sea ice trends in the context of 413 Southern Ocean surface climate variations since 1950. Geophys. Res. Lett. 41, 2419-2426 414 (2014).

415 44. Zhang, L., Delworth, T. L., Cooke, W. \& Yang, X. Natural variability of Southern Ocean 416 convection as a driver of observed climate trends. Nat. Clim. Change 9, 59-65 (2019).

417 45. Fogt, R. L. \& Connolly, C. J. Extratropical Southern Hemisphere synchronous pressure 418 variability in the early twentieth century. J. Clim. 34, 5795-5811 (2021).

419 46. Fogt, R. L. et al. Historical SAM Variability. Part II: Twentieth-Century Variability and 420 Trends from Reconstructions, Observations, and the IPCC AR4 Models. J. Clim. 22, 5346$4215365(2009)$. 
422 47. Schneider, D. P. \& Fogt, R. L. Artifacts in Century-Length Atmospheric and Coupled

423 Reanalyses Over Antarctica Due to Historical Data Availability. Geophys. Res. Lett. 45,

$424 \quad 964-973(2018)$.

425 48. Rayner, N. A. et al. Global analyses of sea surface temperature, sea ice, and night marine air 426 temperature since the late nineteenth century. J. Geophys. Res. 108, (2003). 


\section{Total Sea Ice Extent, 1905-2020}

a) DJF

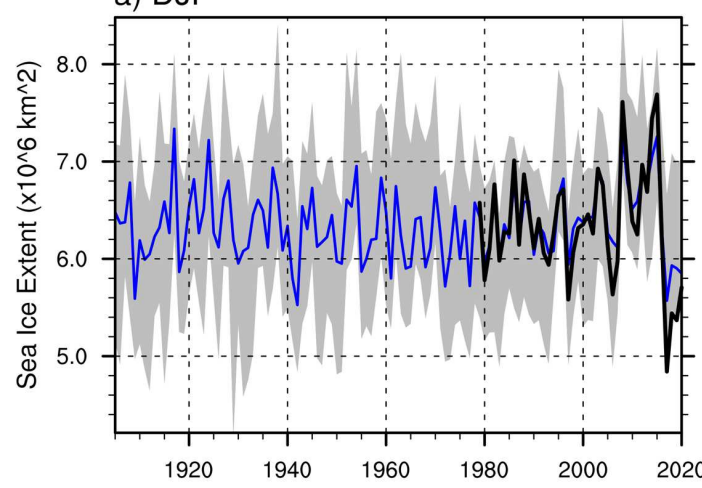

c) JJA

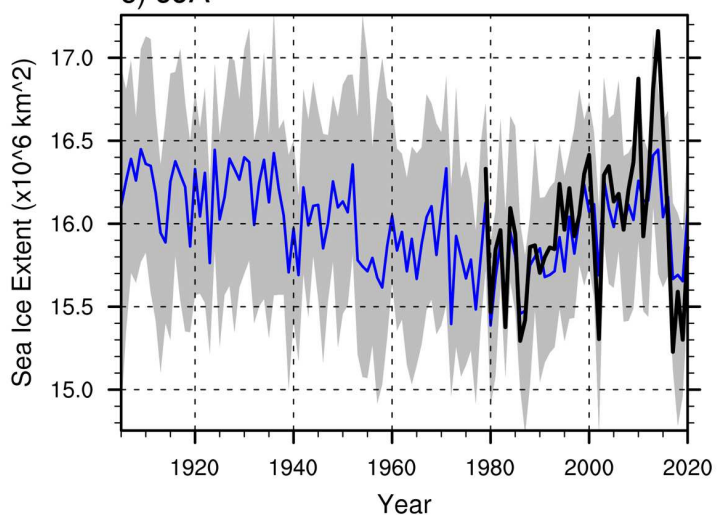

b) MAM

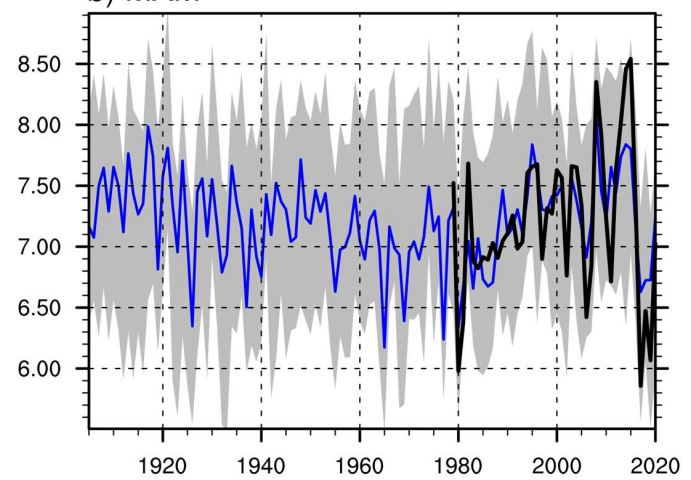

d) $\mathrm{SON}$

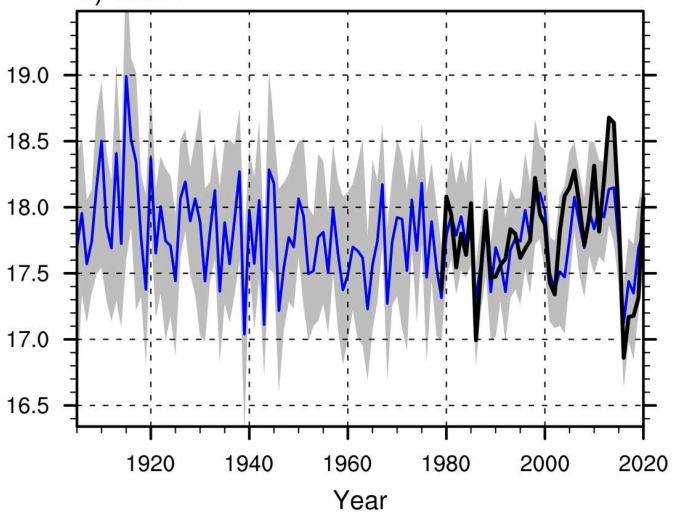

429

430

431

432

433

434

435

436

437

438

Figure 1. Seasonal total Antarctic sea ice extent in the $20^{\text {th }}$ century, with observations depicted in black. The blue line is the ensemble mean reconstruction acquired from the average of over 200,000 possible sums of seasonal sector-based sea ice extent reconstructions, and the gray shading approximates the reconstruction uncertainty as the greater of the two standard deviation spread of the ensemble members or the two standard deviation range of the residuals of an individual best fit reconstruction ensemble member. a) December - February, DJF; b) MarchMay, MAM; c) June - August, JJA; d) September-November, SON. 
Total Sea Ice Extent (Reconstruction vs. Reconstruction Sum), 1905-2020

a) DJF

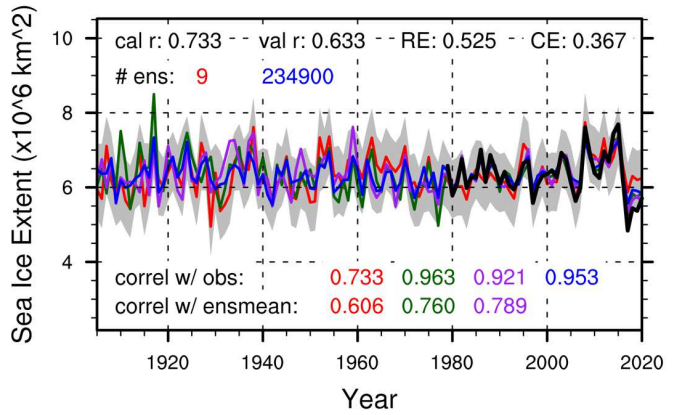

c) JJA

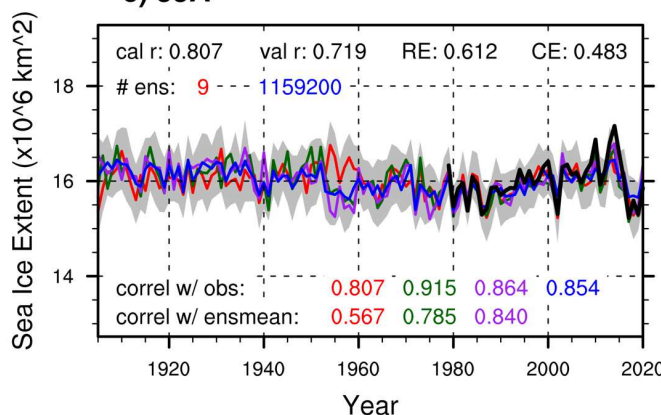

Best Fit Total Reconstruction

Best Fit Summed Sector Reconstructions

Sum of Best Fit Sector Reconstructions b) MAM

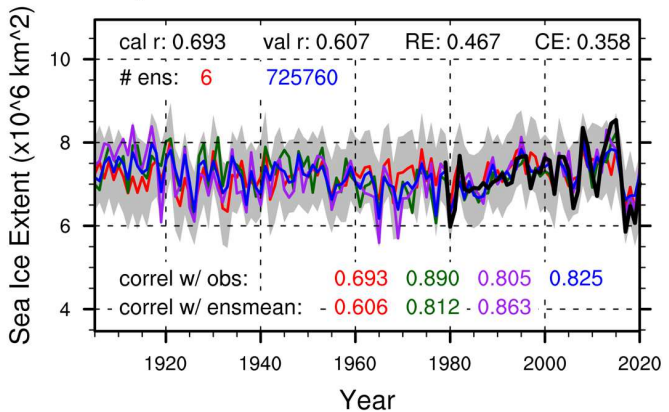

d) SON

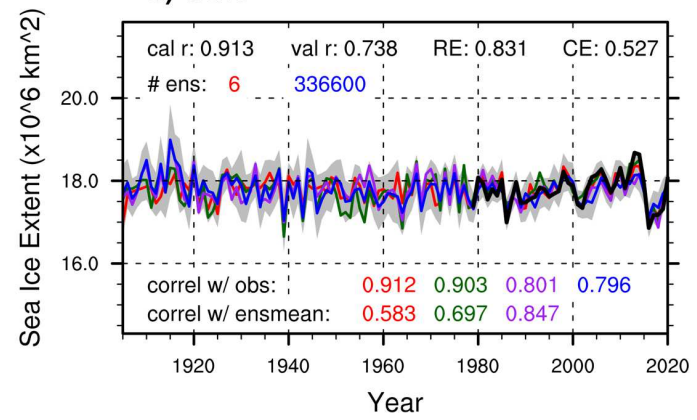

Observed Total Sea Ice Extent
Figure 2. Seasonal timeseries plots of various ways of representing the total Antarctic sea ice extent reconstruction, along with various reconstruction skill metrics for the best-fit reconstruction (red line); cal $\mathrm{r}=$ calibration correlation, $\mathrm{val} \mathrm{r}=$ validation correlation, $\mathrm{RE}=$ reduction of error; $\mathrm{CE}=$ coefficient of efficiency. The best fit reconstruction (red line) was the highest performing ensemble member calibrated specifically to the observed total sea ice extent. The best fit summed sector reconstruction (green line) is the ensemble member from all possible sums of the individual sector ensemble members, while the ensemble mean (blue line) is the average of all these possible sector reconstruction sums. The sum of the best fit sector reconstructions (purple) is the sum of the highest performing sector reconstruction ensemble members that have been specifically calibrated to the observed sector sea ice extent. The correlation of all reconstructions with observations ('correl w/ obs') as well as the correlation of the reconstruction with the ensemble mean ('correl w/ ensmean') is given at the bottom, with the colors representing the various reconstructions labeled in the legend below the figure. The number of ensemble members (\# ens) is also given for the best fit reconstruction (red line, number in red) as well as for the ensemble mean (blue number). 


\section{Reconstruction Seasonal Skill Performance across All Ensembles}

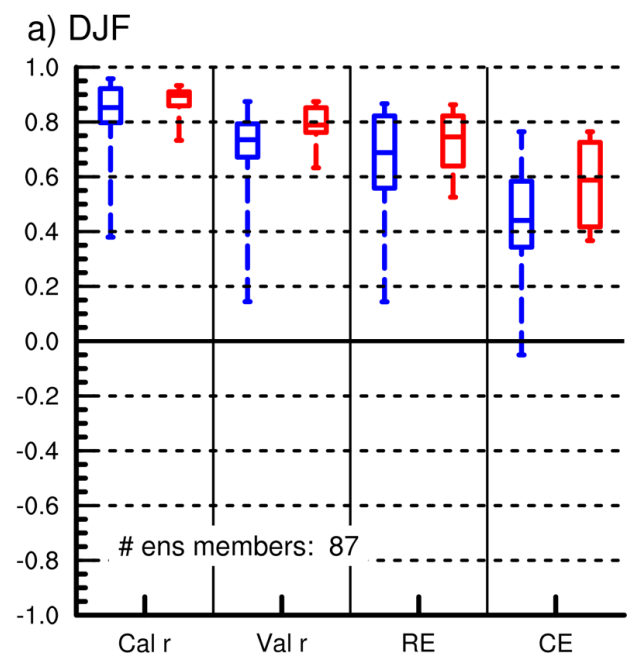

b) MAM

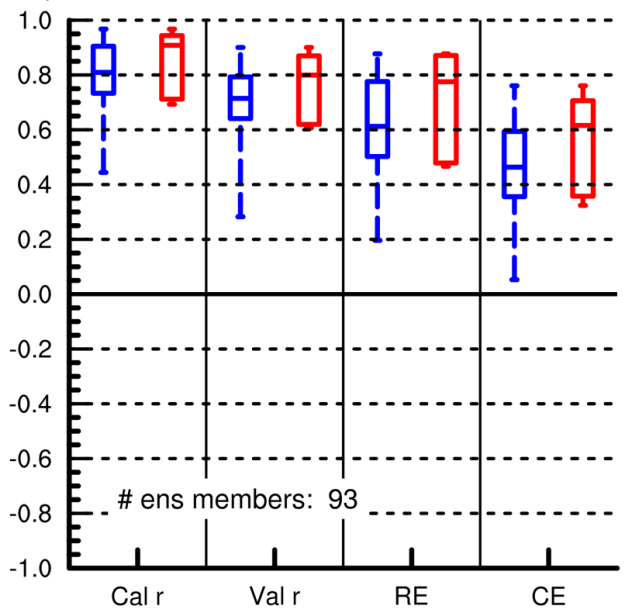

c) JJA

d) $\mathrm{SON}$

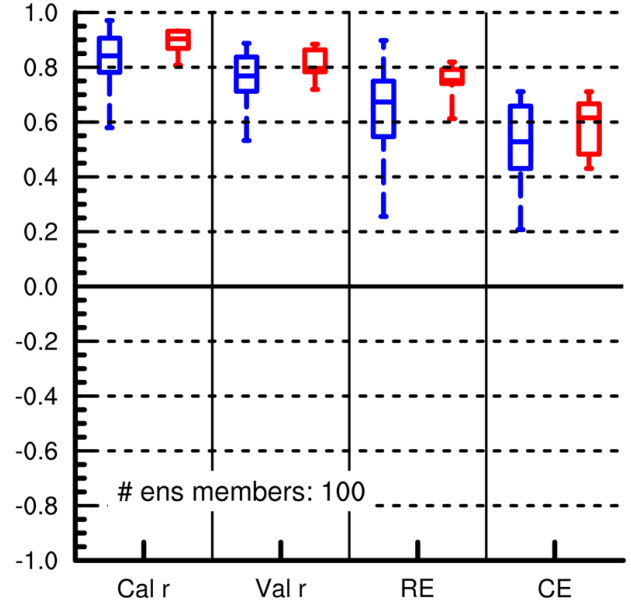

All Ensemble Members

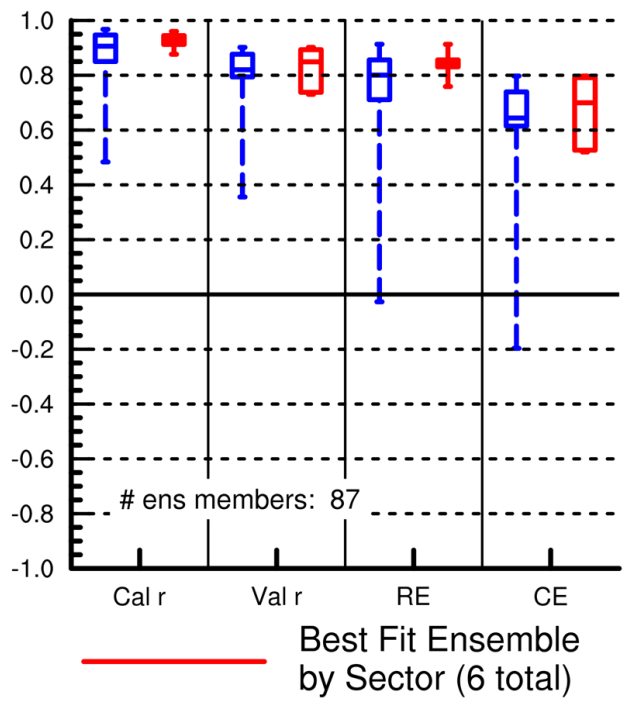

Figure 3. Boxplots of reconstruction performance across all ensembles (blue) and the best fit reconstruction for each sector, including total (red). 


\section{Total Sea Ice Extent Seasonal Time-Varying Trends}
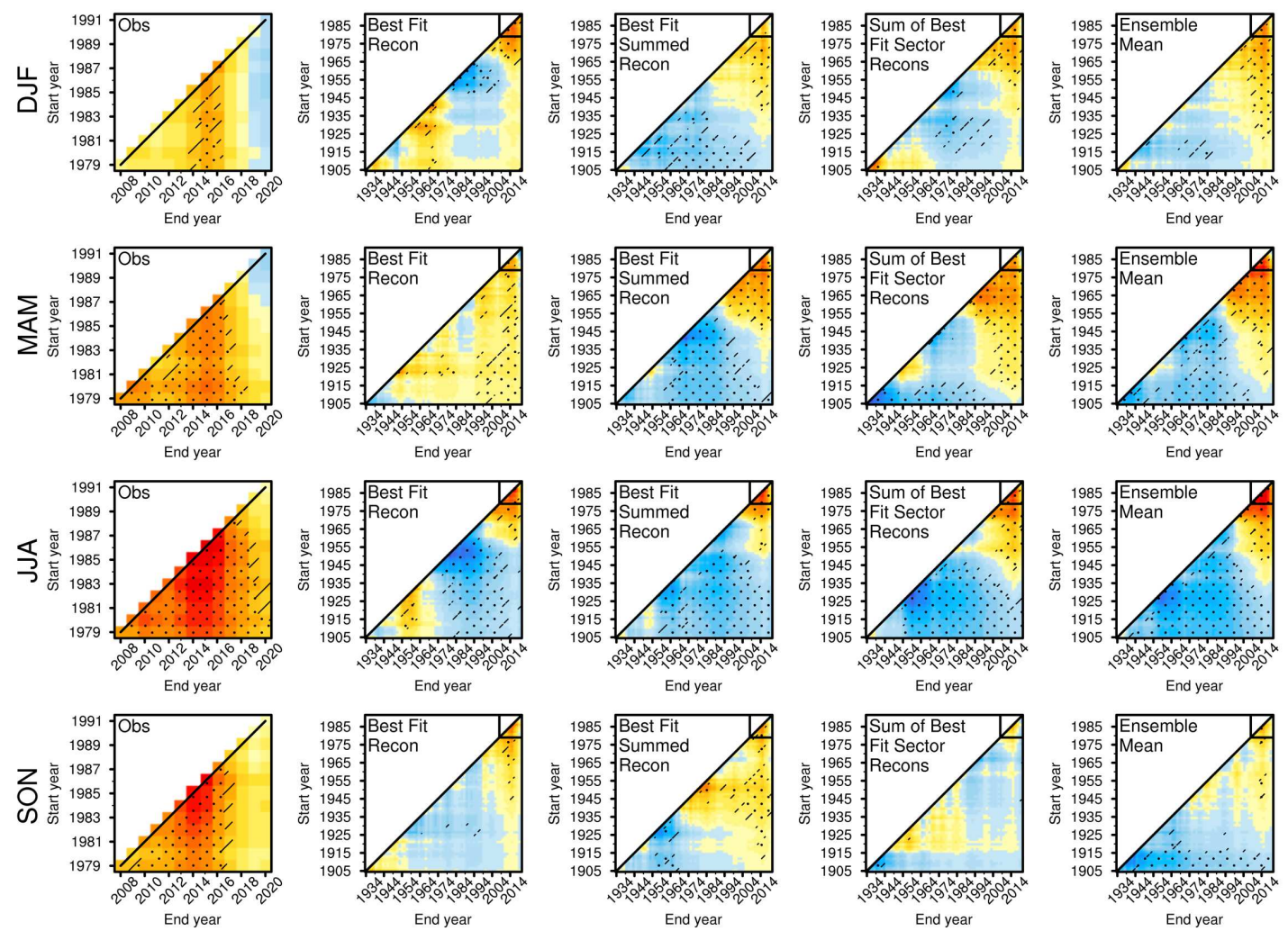

Sea Ice Extent trends (stand dev decade ${ }^{-1}$ )

Figure 4. Time-varying linear trends of standardized seasonal total Antarctic sea ice extent.

The y-axis identifies the starting year for a trend, and the x-axis the ending year for a trend, making the shorter time periods in the upper-left, with longer periods in the lower right of each panel. The diagonal line is exactly 30 years, and trends are only given for periods longer than 30 years. The observations are in the far left column (with different start / end periods), and the remaining columns represent an estimate of the total Antarctic sea ice as described in Fig. 2.

473 Cross-hatching and stippling represent trends that are significantly different from zero at $p<0.10$ and $p<0.05$, respectively. 
JJA Sea Ice Extent Sector Reconstructions, 1905-2020
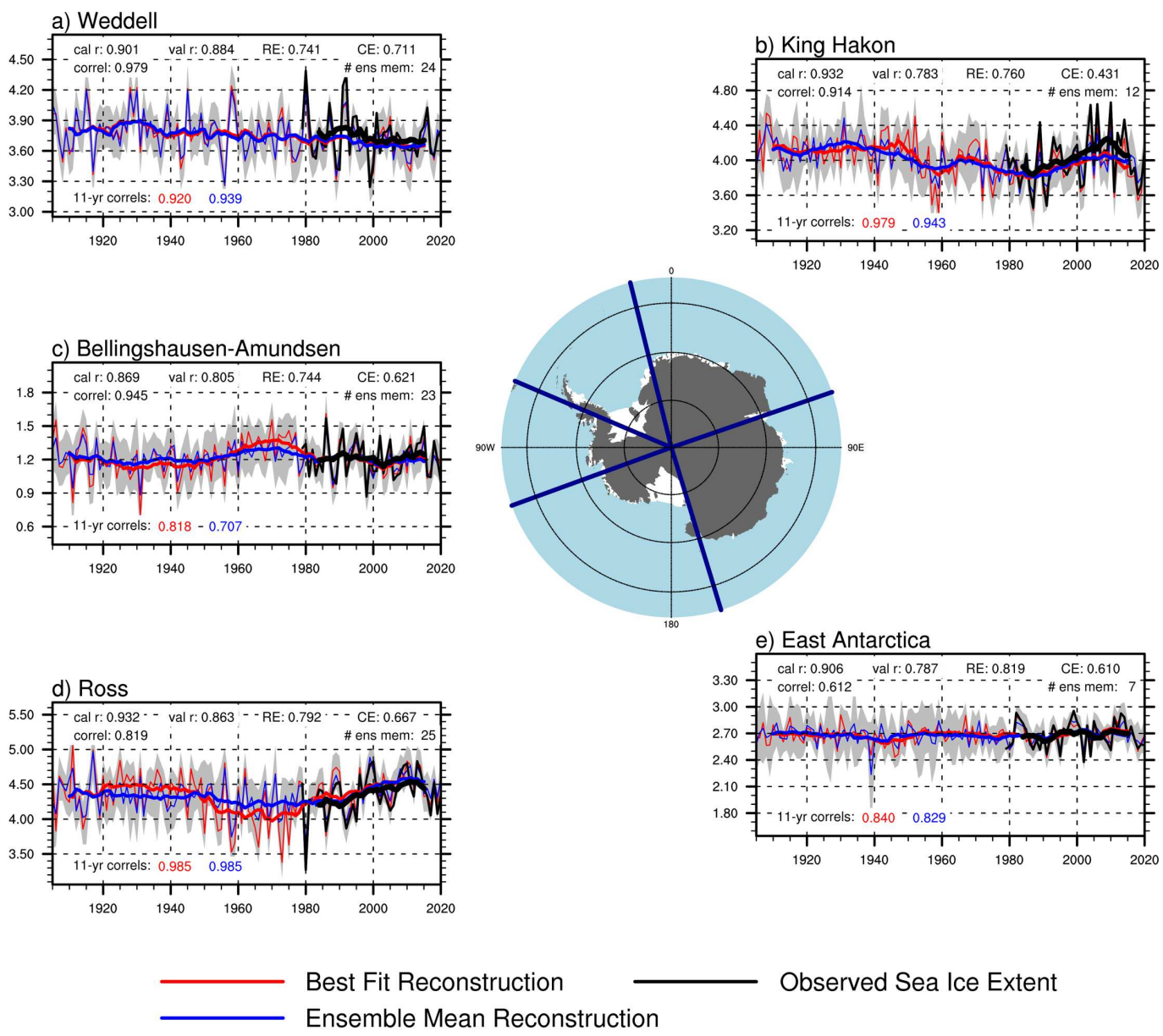

478 Figure 5. Austral winter (JJA) timeseries of the sector reconstructions with a map showing the boundaries of each sector. The thick lines are smoothed versions (with an 11-year running mean) of each timeseries. Given in each panel are the reconstruction skill metrics (detailed in Fig. 1) for the best fit reconstruction (red line), as well as the correlation between the ensemble mean and best fit reconstruction during 1905-2020 ("correl"). The number of ensemble reconstructions produced is given in the upper right, and the correlations of the 11-year smoothed versions with the observed smoothed data are given in the bottom, with the colors representing the best fit (red) or ensemble mean (blue) reconstructions. The gray shading in each panel represents the reconstruction uncertainty, taken as the larger of 1.96 times the standard deviations of the best fit reconstruction compared to the observed, or 1.96 times the standard 


\section{Methods}

Data

The seasonal sea ice extent reconstructions are primarily based on monthly mean pressure and temperature records across the Southern Hemisphere extratropics and midlatitudes from 1905-2020. These records were used in previous research ${ }^{1,2}$ and obtained from the University Corporation for Atmospheric Research research data archive dataset ds570.0 ${ }^{3}$. A few stations were patched with nearby stations using a monthly mean offset, as discussed in earlier work ${ }^{2}$. Data for the stations in South Africa (Cape Town, Durban, and Port Elizabeth) were updated through 2020 by creating monthly means from the daily data in the National Centers for Environmental Information Global Summary of the Day dataset ${ }^{4}$. Beyond the direct observations of temperature and pressure, indices of modes of climate variability were also used as potential predictors of Antarctic sea ice extent. These include the Interdecadal Pacific Oscillation (IPO) $)^{5}$, which is calculated using the difference of sea surface temperature (SST) anomalies averaged in the central equatorial Pacific, the northwest Pacific, and the southwest Pacific from the NOAA Extended Reconstructed Sea Surface Temperature dataset, version 5 $\left(\right.$ ERSSTv5) ${ }^{6}$. We also calculate the Niño sea surface temperature indices from ERSSTv5, namely the Niño $1+2 \mathrm{SSTs}$ (averaged over $\left.0^{\circ}-10^{\circ} \mathrm{S}, 270^{\circ}-280^{\circ} \mathrm{E}\right)$, the Niño $3 \mathrm{SSTs}\left(5^{\circ} \mathrm{N}-5^{\circ} \mathrm{S}\right.$, $\left.210^{\circ}-270^{\circ} \mathrm{E}\right)$, Niño $3.4 \mathrm{SSTs}\left(5^{\circ} \mathrm{N}-5^{\circ} \mathrm{S}, 190^{\circ}-240^{\circ} \mathrm{E}\right)$, and the Niño $4 \mathrm{SSTs}\left(5^{\circ} \mathrm{N}-5^{\circ} \mathrm{S}, 160^{\circ}-\right.$ $\left.210^{\circ} \mathrm{E}\right)$. In addition to these SSTs to monitor the variability associated with these SSTs to monitor the El Niño-Southern Oscillation, we also use the Southern Oscillation Index (SOI), the difference in standardized pressure from Tahiti, French Polynesia, and Darwin, Australia from the Australian Bureau of Meteorology as it does not have any gaps in the $20^{\text {th }}$ century

13 (http://www.bom.gov.au/climate/current/soihtm1.shtml). We also use the index for the Atlantic Multidecadal Oscillation (AMO) ${ }^{7}$. For the Southern Annular Mode (SAM) index ${ }^{8}$, we merge the 
515 'Fogt' seasonal SAM index reconstructions ${ }^{9,10}$, which extend back to at least 1905, with the

516 observationally-based SAM index ${ }^{11}$ after 1957 . In contrast to the other indices, the SAM indices

517 are only available seasonally; all other predictor data are available for each month.

518 We computed sea ice extent (SIE) using satellite-observed sea ice data from Nimbus-7

519 Scanning Multichannel Microwave Radiometer (SMMR) and Defense Meteorological Satellite

520 Program (DMSP) Special Sensor Microwave Imager - Special Sensor Microwave

521 Imager/Sounder (SSM/I-SSMIS). We used the Climate Data Record (CDR) daily concentration

522 fields from the National Oceanic and Atmospheric Administration / National Snow and Ice Data

523 Center (NOAA/NSIDC) Climate Data Record of Passive Microwave Sea Ice Concentration,

524 Version $4^{12}$. The CDR algorithm output combines of ice concentration estimates from the

525 National Aeronautics and Space Administration (NASA) Team algorithm ${ }^{13}$ and the NASA

526 Bootstrap algorithm ${ }^{14}$. The data span the period 25 October 1978 to 31 December 2020 and are

527 daily except prior to July 1987 when they are given every other day. Data are gridded on the

$528 \mathrm{SSM} / \mathrm{I}$ polar stereographic grid $(25 \mathrm{~km} \times 25 \mathrm{~km})$. The SIE used in our analysis is calculated

529 using the equatorward limit of the 15\% sea ice concentration (SIC) isoline. Thus, it is the sum of

530 the area of every grid cell that is $15 \%$ or more covered with sea ice. The monthly SIE was

531 calculated as the average of the SIE for days in that month. In addition to the alternate day

532 observations from 1978 to 1987, there are a number of days and segments of days with no

533 observations. In particular, there are no data between 3 December 1987 and 12 January 1988. For

534 these days we fit a stochastically imputed the daily SIE using the following procedure: We

535 constructed anomalies by subtracting off the invariant annual cycle, estimated using the methods

536 of recent work ${ }^{15}$. We then fit a Bayesian AutoRegressive Integrated Moving Average (ARIMA)

537 model to the observed daily SIE. We then stochastically imputed the missing days by drawing 
538 for their posterior distribution. The monthly SIE values were computed by averaging of all days

539 in the month. We note that, except for the period from 3 December 1987 and 12 January 1988

540 the impact of this stochastic multiple imputation scheme is small. The sectoral SIE was

541 computed as the sum of the area within the sector of every grid cell that is above $15 \%$ or more

542 covered with sea ice (most cells are completely within a single sector). Although contiguous, the

543 sectors are defined based on their spatial decorrelation scale as discussed in earlier work ${ }^{16}$. The

544 longitude bounds for the sectors are as follows: Bellingshausen-Amundsen Seas $\left(250^{\circ}-290^{\circ} \mathrm{E}\right)$,

545 Weddell Sea $\left(250^{\circ}-346^{\circ} \mathrm{E}\right)$, King Hakon VII $\left(346^{\circ}-71^{\circ} \mathrm{E}\right)$, East Antarctica $\left(71^{\circ}-162^{\circ} \mathrm{E}\right)$ and Ross

546 Sea $\left(162^{\circ}-250^{\circ} \mathrm{E}\right)$; the total Antarctic sea ice extent represents the area of all sea ice surrounding

547 Antarctica, and is precisely equal to the sum of the areas in the five sectors.

\section{Reconstruction Methodology}

The seasonal sea ice extent reconstructions follow previous work on early Antarctic

550 climate using a proven principal component regression technique ${ }^{1,17-19}$. We first compute

551 seasonal means of the various predictor data, and correlate these with the sea ice extent time-

552 series that is being reconstructed; all data are linearly detrended prior to correlation. To

553 indirectly account for the slower response of the sea ice to the atmosphere and the role of the

554 ocean in this relationship, we also correlate predictor data which lead the Antarctic sea ice extent

555 data for up to one season, at increments of one month. For example, if reconstructing sea ice

556 extent for June-August (JJA), correlations of predictors with JJA sea ice extent are computed for

557 predictor data averaged in JJA (no lag), May - July (MJJ, 1 month lead), April - June (AMJ, two

558 months lead), and March-May (MAM, 3 months or one season lead). We perform one separate

559 ensemble reconstruction using all temperature and pressure observations (regardless of

560 correlation magnitude), and smaller networks of predictor data, including indices of climate 
561 variability (see Fig. S1), that are significantly correlated at $p<0.10, p<0.05, p<0.025$, and $p<0.01$.

562 These increasing smaller sets of predictor data comprise our predictor data networks (5 total).

563 We then subsequently add on beyond the temperature and pressure observations any indices of

564 climate variability correlated at the various thresholds for each data network; these additions

565 comprise our data layers. The climate index layers (in order of layering) are: The IPO, AMO,

566 PDO, SOI, Niño 1+2 SSTs, Niño 3.4 SSTs, Niño 3 SSTs, Niño 4 SSTs, and the SAM index.

567 Altogether, the combination of data predictor networks (based on the significance of the

568 correlation between predictors and sea ice extent time-series we are reconstructing) and the data

569 layers (adding on significantly correlated climate indices) constitutes a possibility of up to 41

570 ensemble members for each reconstruction (4 data networks times 10 data layers plus 1 ensemble

571 member which employs all observations regardless of correlation magnitude).

572 Once the predictor data are selected using the above procedure, principal component

573 analysis is performed using the retained standardized predictor data (each variable is

574 standardized over the time period 1905-2020), including predictor data which lead the sea ice by

575 up to one season. We limit the number of factors calculated in the principal component analysis

576 to a maximum of 35 to expedite the computations. A subset of these principal components

577 (PCs), sorted by the absolute magnitude of their correlation with the sea ice extent time-series

578 being reconstructed, is then regressed onto the sea ice extent time series during 1979-2020 (our

579 calibration period) to fit the reconstruction model. The reconstruction can then be obtained using

580 the relationships the PCs share with the sea ice extent time-series (the regression coefficients)

581 and the relationships the PCs share with the individual predictor data (PC expansion weights).

582 Combining the regression and PC weights through matrix multiplications yields a value for each

583 predictor variable, sometimes called the beta weights. These beta weights can then be used on 
584 the full length of the observed predictor data to obtain the reconstruction back until 1905.

585 Alternatively, the PCs can similarly be extended back to 1905 using the predictor data and used 586 with the regression coefficients to perform the reconstruction.

587 The ideal number of PCs to retain for the regression model is based on an independent 588 validation procedure (leave-one-out cross validation) employed in previous work ${ }^{1,17,19}$. Here, we 589 repeat the PC regression model one time for each year in the observed record (cailbration period) 590 from 1979-2020 (42 times), each time leaving an individual year and its two neighboring years

591 before and after (a total of up to 5 years) out. The center year is thus assumed to be independent

592 of the remaining retained years and is predicted using the weights generated in the reconstruction 593 model described above. Predicting each year independently and concatenating the predicted 594 values yields an entirely predicted and independent timeseries we call the validation 595 reconstruction. This reconstruction is correlated to the observed sea ice extent data (giving the 596 skill metric we call validation correlation, or val r), and used separately to compute the 597 coefficient of efficiency (CE) as discussed in earlier work ${ }^{20}$. After the CE is determined, the 598 entire validation procedure is repeated by adding one more $\mathrm{PC}$ at a time to the regression model. 599 The reconstruction that yields the highest $\mathrm{CE}$ is selected as the best performing and retained 600 ensemble reconstruction for that particular data network and data layer. Selecting the highest CE 601 aids in limiting model overfitting, as the $\mathrm{CE}$ will reach a peak and sharply decline and often go 602 very negative as more PCs are added to the regression; this sudden decline is a key indicator of 603 model overfitting despite the overall calibration correlation continuing to increase. Furthermore, 604 only retaining a subset of the PCs makes this regression approach superior to multiple linear 605 regression, as we effectively filter out unwanted noise by only retaining the most strongly 606 correlated PCs. The entire procedure is then reproduced for each data network and data layer to 
607 yield at least 5 ensemble reconstruction members for each season and sector. The number of

608 ensembles for a given sea ice extent reconstruction is dependent on the number of additional data 609 layers employed beyond the temperature and pressure observations.

610 Once all ensemble reconstructions are produced, the best fit ensemble member (red lines

611 in the main paper, one for each season / sector of Antarctic sea ice extent) is first selected by 612 extracting the reconstruction with the highest $\mathrm{CE}$ across all the ensemble reconstructions. To 613 perform an additional check for model overfitting, the variance of the reconstruction in the 614 period 1905-1978 is compared with the reconstruction variance in 1979-2020 and the observed 615 variance in 1979-2020. If the reconstruction variance is significantly $(p<0.01)$ larger than the 616 observed reconstruction, there is a possibility of overfitting occurring. In these few cases, the 617 best fit reconstruction was selected as the next highest $\mathrm{CE}$ where the variances were not 618 statistically significantly different from the observed variance during 1979-2020, if possible. In 619 some cases there were no alternative reconstruction ensemble members with equal variances, and 620 the highest CE was still selected as the best fit reconstruction. This procedure was repeated for 621 each season and sector to create the full array of ensemble and best-fit sector reconstructions.

622 The total reconstruction was produced separately following the above principal 623 component regression model, as was done for each sector. It was also estimated using the sum 624 of the sector best fit reconstructions, since the observed sea ice extent for all sectors sum up to 625 the total sea ice extent. Since each sector had multiple ensemble reconstructions, it is important 626 to check to see how the sum of all possible ensemble member combinations across the sector 627 compare. These combinations constitute more than 200,000 possible combinations for each 628 season (there are over 1 million possible combinations in JJA). We therefore also provide an 629 additional estimate from these combinations by selecting the combination which is most 
630 correlated with the observed sea ice extent timeseries (green line in Fig. 2 in main paper). We

631 use this and the full ensemble spread to further estimate reconstruction uncertainty.

\section{Statistical Methods}

633 Statistical significance of correlation coefficients and regression coefficients (for linear

634 trends of Antarctic sea ice extent) is calculated using a Student's $t$-test, with $\mathrm{n}$-2 degrees of

635 freedom. In making these calculations, we assume each year is independent from every other 636 year.

637

638 Methods References

639 1. Fogt, R. L. et al. Antarctic station-based seasonal pressure reconstructions since 1905: 1.

640 Reconstruction evaluation: Antarctic Pressure Evaluation. J. Geophys. Res. Atmospheres

$641 \quad \mathbf{1 2 1}, 2814-2835(2016)$.

642 2. Fogt, R. L. \& Connolly, C. J. Extratropical Southern Hemisphere synchronous pressure

643 variability in the early twentieth century. J. Clim. 34, 5795-5811 (2021).

644 3. World Monthly Surface Station Climatology. (1981).

645 4. National Centers for Environmental Information. Global Surface Summary of the Day. $646 \quad(2021)$.

647 5. Henley, B. J. et al. A Tripole Index for the Interdecadal Pacific Oscillation. Clim. Dyn. 45, $648 \quad 3077-3090(2015)$.

649 6. Huang, B. et al. Extended Reconstructed Sea Surface Temperature Version 4 (ERSST.v4).

650 Part I: Upgrades and Intercomparisons. J. Clim. 28, 911-930 (2015). 
651 7. Enfield, D. B., Mestas-Nuñez, A. M. \& Trimble, P. J. The Atlantic Multidecadal Oscillation 652 and its relation to rainfall and river flows in the continental U.S. Geophys. Res. Lett. 28, $653 \quad 2077-2080(2001)$.

654 8. Fogt, R. L. \& Marshall, G. J. The Southern Annular Mode: Variability, trends, and climate 655 impacts across the Southern Hemisphere. WIREs Clim. Change 11, (2020).

656 9. Fogt, R. L. et al. Historical SAM Variability. Part II: Twentieth-Century Variability and 657 Trends from Reconstructions, Observations, and the IPCC AR4 Models. J. Clim. 22, 5346$658 \quad 5365(2009)$.

659 10. Jones, J. M. et al. Historical SAM Variability. Part I: Century-Length Seasonal 660 Reconstructions. J. Clim. 22, 5319-5345 (2009).

661 11. Marshall, G. J. Trends in the southern annular mode from observations and reanalyses. $J$. $662 \quad$ Clim. 16, 4134-4143 (2003).

663 12. Meier, W., Fetterer, F., Windnagel, A. \& Stewart, S. NOAA/NSIDC Climate Data Record of 664 Passive Microwave Sea Ice Concentration, Version 4. (2021) doi:10.7265/EFMZ-2T65.

665 13. Cavalieri, D. J., Gloersen, P. \& Campbell, W. J. Determination of sea ice parameters with the $666 \quad$ NIMBUS 7 SMMR. J. Geophys. Res. Atmospheres 89, 5355-5369 (1984).

667 14. Comiso, J. C. Characteristics of Arctic winter sea ice from satellite multispectral microwave $668 \quad$ observations. J. Geophys. Res. 91, 975 (1986).

669 15. Handcock, M. S. \& Raphael, M. N. Modeling the annual cycle of daily Antarctic sea ice 670 extent. The Cryosphere 14, 2159-2172 (2020).

671 16. Raphael, M. N. \& Hobbs, W. The influence of the large-scale atmospheric circulation on 672 Antarctic sea ice during ice advance and retreat seasons. Geophys. Res. Lett. 41, 5037-5045 673 (2014). 
674 17. Fogt, R. L. et al. A twentieth century perspective on summer Antarctic pressure change and 675 variability and contributions from tropical SSTs and ozone depletion. Geophys. Res. Lett. 44, $676 \quad 9918-9927$ (2017).

677 18. Clark, L. \& Fogt, R. Southern Hemisphere Pressure Relationships during the 20th Century678 Implications for Climate Reconstructions and Model Evaluation. Geosciences 9, 413 (2019).

679 19. Fogt, R. L. et al. Seasonal Antarctic pressure variability during the twentieth century from spatially complete reconstructions and CAM5 simulations. Clim. Dyn. (2019)

20. Cook, E. R., Meko, D. M., Stahle, D. W. \& Cleaveland, M. K. Drought reconstructions for the continental United States. J. Clim. 12, 1145-1162 (1999).

687 Code Availability

688 The reconstruction as well as all figures were generated using the NCAR Command Language.

689 All code used to perform the reconstructions and generate the plots are available from the 690 corresponding author upon request, and will be hosted, along with the ensemble reconstructions, 691 on a public data repository and the National Snow and Ice Data Center soon after publication.

\section{Contributions}

694 R.L.F., M.N.R. and M.S.H conceived the study. R.L.F. and A.M.S. performed the

695 reconstructions. R.L.F. led the writing of the manuscript and produced all the figures in the

696 paper. All authors analyzed the results and assisted in writing and editing the manuscript. 
698 Acknowledgments

699 All authors acknowledge support from the National Science Foundation Office of Polar

700 Programs. R.L.F. and A.M.S. were supported by grant OPP-1744998, and M.N.R. and M.S.H.

701 were supported by grant OPP-1745089.

702

703 Competing Interests

704 The authors declare no competing financial and non-financial interests. 


\section{Supplementary Files}

This is a list of supplementary files associated with this preprint. Click to download.

- fogtetalnccsupplementary.docx

- fogtetalnccsupplementary.docx 